\title{
Fotografia, registro sem documento
}

\author{
Maria Cecilia C. Carboni' \\ https://orcid.org/0000-0002-2404-4484 \\ I - Universidade Paulista \\ São Paulo (SP), Brasil
}

Resumo: Este artigo propõe pensar outra possível história que as fotografias contam sobre a Revolta de 1924, entendendo-as como diferentes narrativas sobre o evento em questão. Nesse sentido, investiga a transgressão do conceito tradicional da fotografia como documento da realidade, observando que a fotografia promove outro tipo de narrativa que vai além do registro como documentação histórica. Para tanto, o artigo fundamenta-se em conceitos e reflexões trazidos por vários autores, como Carlo Ginzburg sobre o conceito de rastro, François Dosse e Mauricio Lazzarato nas respectivas interpretações do conceito de acontecimento e Joan Fontcuberta, Vilém Flusser, Walter Benjamin e Lucrécia Ferrara que apontam outras relações entre a fotografia e a comunicação, além da bibliografia sobre a Revolta de 1924.

Palavras-chave: fotografia; rastros; genealogia; acontecimento; Revolta de 1924.

Abstract: Photography, record without document - This paper proposes to think of another possible story told by photographs about the Revolt of 1924, understanding them as different narratives about the event in question. In this sense, it studies the transgression of the traditional concept of photography as a document of reality. It is observed that photography promotes another type of narrative that goes beyond the record as historical documentation. For this, the paper is based on concepts and reflections brought by various authors, such as Carlo Ginzburg on the concept of trail, François Dosse e Mauricio Lazzarato, about the concept of event, Joan Fontcuberta, Vilém Flusser and Walter Benjamin, who permeate the discussions about photography, Lucrécia D’Alessio Ferrara, on the issues related to communication, in addition to the bibliography on the Revolt of 1924 .

Keywords: photography trail; genealogy; event; Revolt of 1924.

\section{A Revolta e seu contexto}

A Revolta de 1924, evento histórico ocorrido na cidade de São Paulo, inicia-se como um levante de alguns militares, em sua maioria tenentes, opositores do presidente 
Arthur Bernardes. Ela é parte de um conjunto de eventos que abalaram os primeiros anos da República no Brasil, entre eles o tenentismo que, no entanto, não se identificava ideologicamente com os movimentos operários de orientação anarquista ou comunista, nem com os partidos da elite paulistana. Esses últimos se manifestariam pouco tempo depois, contrariamente ao golpe conduzido por Getúlio Vargas em 1930, que rompeu com as alianças políticas que deram manutenção à alternância de poder. Foi pela força e truculência que Arthur Bernardes conseguiu exercer o mandato já iniciado com uma crise política na própria posse, em 1922. Dessa forma, manteve-se presidente e teve que lidar com outras revoltas, como a do Rio Grande do Sul, em outubro de 19241', e outras tentativas, como no estado do Mato Grosso, em Aracaju, em Manaus e em Belém (PEREIRA, 2010).

A tentativa de tomada do poder alternou conquistas e derrotas, ações de grande êxito e imprevistos e resultou na derrota e fuga dos militares revoltosos em direção ao sul do país. Nos dias seguintes ao início do levante, os próprios revoltosos tentaram restabelecer a ordem na cidade por meio do monitoramento e da vigilância das ruas. Quando os ataques das tropas federais começaram a atingir civis, os revoltosos tentaram auxiliar a população patrocinando o socorro e o atendimento a feridos e famílias em fuga.

Muitos componentes das camadas médias urbanas manifestaram-se favoravelmente à rebelião. Entre os indiciados no movimento de 1924 aparecem componentes das camadas médias urbanas: professores, estudantes, comerciários, funcionários (CORREA, 1974, p. 158).

A falta de organização e força bélica dos tenentes permitiu que a revolta durasse apenas 22 dias e não atingisse seu objetivo final, que era a deposição do presidente da República. Nessa época, a cidade de São Paulo encontrava-se em período de transição e passava da economia agrícola para a industrial, causando desestabilização econômica e social, além de reflexos urbanos e arquitetônicos, artísticos e intelectuais. O sopro do moderno trouxe o projeto de transformar a província em metrópole com o patrocínio da elite paulistana. Mas não é possível isolar esses fatos da Revolução Russa (1917) e da dinâmica política estabelecida pela Primeira Guerra Mundial (1914-1918).

Foi no contexto da Guerra, por exemplo, que as novas técnicas de racionalização industrial e gerenciamento científico se consolidaram e obtiveram sua consagração definitiva, dando pleno curso aos mercados de massa (SEVCENKO, 1992, p.164-165).

\section{As mudanças provocadas pela fotografia}

O começo do século XX registra profunda transformação na experiência comunicativa inaugurada pela fotografia, uma experiência que vai além das informações trazidas pelas fontes documentais pertencentes à linguagem escrita. A presença da fotografia amplia e questiona as abordagens narrativas mais tradicionais que a história realiza diante dos documentos. Com forte influência da Escola dos Annales, a fotografia passa a ser aceita como documento, ainda que com ressalvas até os dias de hoje.

1 Essa revolta foi liderada pelo jovem capitão do Exército e tenentista Luís Carlos Prestes. 
A dificuldade da história em trabalhar com documentos fotográficos é marcada pela escassez de pesquisas historiográficas feitas por meio de fotografias, ou seja, pesquisas que usam a fotografia para análise e conhecimento histórico. Vale ressaltar a diferença entre produzir uma história da fotografia e produzir história pela fotografia. Ainda que a história da fotografia fale das várias dimensões contextuais do aparelho fotográfico e sua evolução, a história feita por meio da fotografia pode trazer elementos de outra ordem da documentação, pois a linguagem fotográfica permite que a pesquisa se torne ainda mais indagativa.

Considerando sua natureza polissêmica, observa-se que a fotografia possibilita reconhecimentos, revelações e ampliações que estendem a documentação dos eventos históricos. É possível apreender informações que poderiam passar desapercebidas, ou que sequer tenham sido notadas, evidenciando que a fotografia vai além da simples cópia do referente. Nesse contexto, a abordagem mais recente da pesquisa historiográfica propõe uma ampliação da análise desses documentos e, como consequência, passa a questionar o valor histórico dos documentos verbais.

Nos anos 70, o historiador Pierre Nora (1997) observou que a fotografia se insere como outra escrita da história, permitindo valorizar os arquivos visuais. Além dele, o historiador Carlo Ginzburg (2006), ao estudar a Idade Média, observou que não é nova a tendência de tangenciar a documentação histórica por meio de elementos inventados. As pesquisas desses historiadores ecoam nos trabalhos de Jacques Le Goff (1990), Marc Bloch (2002), Peter Burke (1991), Michel Frizot (2001), Rogier Chartier (1993), entre outros. Le Goff (1990) aponta que o surgimento da imprensa modifica a maneira como construímos a memória, já que a memória é o lugar onde a história cresce. Marc Bloch (2002, p. 64) ressalta a impossibilidade de mudarmos o passado, mas aponta que "o conhecimento do passado é uma coisa em progresso, que incessantemente se transforma e se aperfeiçoa". Peter Burke (1991) fala de protagonistas históricos que escapam da narrativa oficial: a história passou a ser feita no plural, considerando subjetividades, microfenômenos visuais, pessoas anônimas e o cotidiano, além de repensar os questionamentos feitos aos documentos, até então tidos como únicos portadores dos fatos.

As fotografias da Revolta de 1924 cumprem sua função como registro. Entretanto, se trabalharmos com elementos negligenciados na visualidade fotográfica, podemos propor perguntas que extrapolam a ideia de registrar. Nessa prática comunicativa de base indagativa, notamos um aspecto interativo revelador da informação fotográfica que vai além do simples dado registrado. Supera-se o entendimento da informação como transmissão de um dado e evidencia-se a comunicação como o que propõe a interação entre aquilo que se mostra e aquilo que se vê, ou seja, a fotografia mais sugere do que registra e, assim, a comunicação passa a revelar o inusitado daquilo que se mostra, mas não se vê. A comunicação aprende, com a informação, que é possível ir além da transmissão e transformar a banalidade visual em elemento que interage entre múltiplos e distintos olhares.

É necessário, também, destacar a diferença entre o conceito de imagem e de fotografia. Para Vilém Flusser (2002), a fotografia é uma imagem técnica, ou seja, uma imagem produzida por aparelhos técnicos. As imagens ditas tradicionais são abstrações, 
ligadas à pré-história e aos textos, já as imagens técnicas "imaginam textos que concebem imagens que imaginam o mundo" (ibidem, p.13), por isso são pós-históricas e nos levam a conhecer apenas alguns aspectos ou conceitos relativos ao mundo e não "o mundo". Conforme a reflexão de Flusser, observa-se que o que chama atenção nas imagens da Revolução de 1924 é exatamente o que essas fotografias não mostram: a Revolta. A partir dessa constatação, perguntamos: pode a fotografia registrar sem documentar? Ou: poderia a fotografia documentar exatamente ao registrar o irrelevante?

A fotografia comporta ambivalências no contexto fotográfico e rever seu papel como registro e sua influência nas tessituras da realidade possibilita admitir suas potências. Quando se insiste nas perguntas e não nas informações viciadas do referente, é possível fabular e tornar imaginário o próprio registro, algo que se coloca como a potência oposta ao registro fotográfico, sem excluí-lo. Em pelos menos quatro acervos, ${ }^{2}$ encontramos quatro imagens sugestivas. Se entendermos as fotografias como registro, nelas veremos, respectivamente, uma fábrica atacada por bombas, uma casa destruída enquanto uma mulher sai tranquilamente pela porta e uma bomba que não explodiu com estranho aviso de perigo possível, mas não provável, em um dos ataques feitos às indústrias da cidade. Veremos exatamente aquilo que a fotografia faz ser evidente e demonstrativo. Então perguntamos: que tipo de conflito é esse? Como a cidade e seus moradores reagem ao conflito? Não Ihe dão a gravidade devida? Não há medo? Ou é maior a pressa dos afazeres cotidianos?

Entendemos fabulações como uma "atividade transdutora que, mais do que tradução, leva a reconhecer, ou conhecer outra vez, a realidade e o mundo" (FERRARA, 2018, p. 15). Isso significa rever as fotografias da Revolta e passar a compreendê-las de outra forma, como um conteúdo fotográfico, que, de fato, não mostra a revolta. O que muda nessa colocação é o modo como as fotografias podem ser entendidas, pois não revelam a Revolta: elas podem ser documentos de fatos relativos ao evento, mas não necessariamente um documento da Revolta.

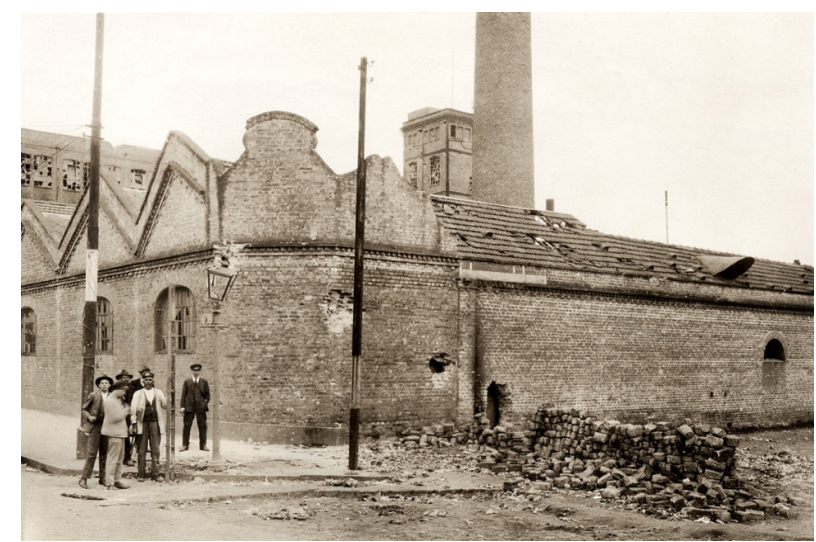

Fig. 1. A. de Barros Lobo, Fábrica Crespi após bombardeios, Mooca, São Paulo, 1924. Fonte: Acervo Instituto Moreira Salles, São Paulo, 2015.

2 São eles: Instituto Moreira Sales, Fundação de Saneamento e Energia, Museu da Polícia Militar e O Estado de São Paulo. 


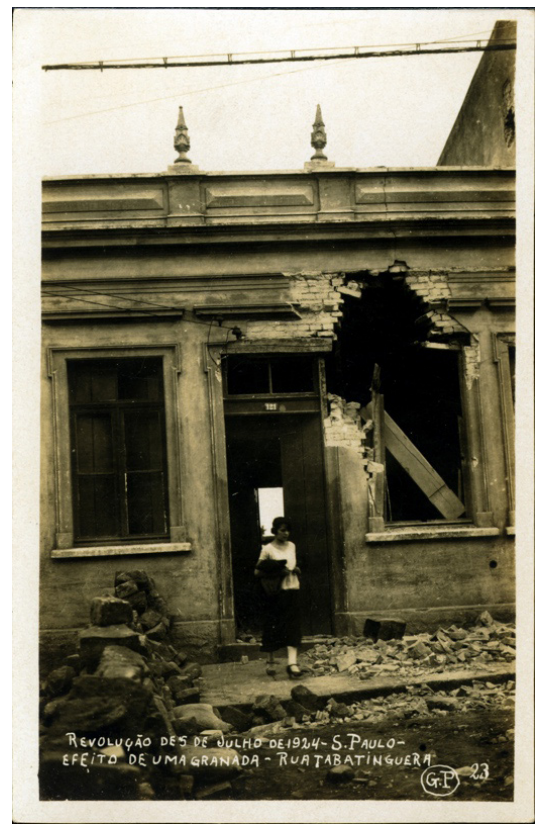

Fig. 2. Gustavo Prugner, Efeito de uma granada na rua Tabatinguera, São Paulo, 1924. Fonte: Acervo Instituto Moreira Salles, São Paulo, 2015.

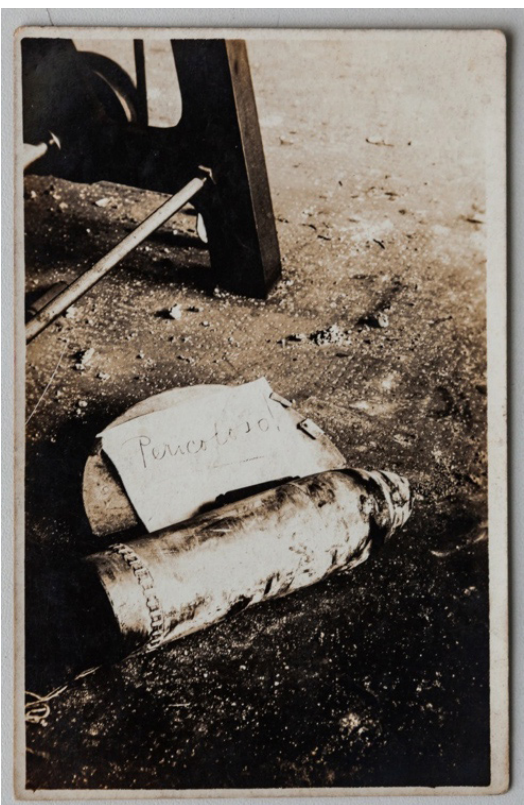

Fig. 3. Autoria desconhecida, Granada que não explodiu na Fábrica Crespi, São Paulo, 1924 Fonte: Acervo Fundação Energia e Saneamento, São Paulo, 2015. 


\section{A fotografia pergunta}

O objetivo da pesquisa que deu origem a esse artigo não é recuperar fontes documentais da Revolta, mas perceber de qual revolta as fotografias falam, pois falam, de fato, de outra Revolta de que as fontes ditas oficiais - como documentos judiciais ou governamentais, ou ainda, as próprias fontes historiográficas sobre a Revolta - não falam. Por isso a fotografia, neste caso, não é documento, pois diferentemente da expectativa de cumprir essa função, falha quando possibilita outras versões narrativas sobre a Revolta de 1924. Desse modo, pode-se perguntar: esse conflito teria tido a intensidade e abrangência na cidade como querem atestar as fontes oficiais? A possibilidade da dúvida, por si só, já nos aponta a falha da fotografia em documentar aquilo que registra.

Lembramos aqui a "fábula do olhar" de George Didi-Huberman (2010). O autor fala de um dentro e de um diante da imagem. Ainda que essa pesquisa não se valha de referências da história da arte, deve-se notar a ambivalência entre o estar diante e o estar dentro, no caso das fotografias, pois o estar dentro das fotografias é de fato fazer as perguntas, enquanto o estar diante é aceitá-las apenas como registro. Um estar entre é o lugar da ambivalência, "e essa desconfortável postura define toda a nossa experiência, quando se abre em nós o que nos olha no que vemos" (ibidem, p. 234).

Por meio de fotografias é possível ter contato com rastros de um passado, como uma bomba que não explodiu ou uma mulher que sai de casa destruída por um bombardeio como quem sai corriqueiramente para trabalhar. Por isso, para Pierre Nora (1997), a fotografia estabelece uma relação descontínua com o tempo passado, pois joga com o tempo cronológico, subvertendo sua lógica, indagando sobre de que tempo fala a fotografia em questão. Já o historiador Paul Veyne (1998) nos lembra que os eventos são parciais, incompletos, laterais e que a história tem natureza lacunar. "Como um romance, a história seleciona, simplifica, organiza, faz com que um século caiba numa página e essa síntese da narrativa é tão espontânea quanto a da nossa memória, quando evocamos os dez últimos anos que vivemos" (ibidem, p. 18).

Veyne (ibidem) lembra que nossa memória condensa o tempo de modo discreto, revela pontos que compõem os fatos, mas que passam desapercebidos e, para serem iluminados, requisitam conexões que Ihes permitam ganhar força. Essas conexões entre pontos discretos são rastros que falam de uma genealogia histórica entre fatos distantes no tempo, mas fazem ecoar, por meio da enunciação que os apresenta, a história de outro tempo e, então, o passado faz-se presente. Genealogicamente, lê-se a história por meio de enunciações históricas distantes: "o curso dos acontecimentos não caminha numa rota traçada" (ibidem, p. 45). Os rastros podem revelar informações que ignorávamos por serem aparentemente algo irrelevante ou menor. Em análoga reflexão, Carlo Ginzburg (1989) propõe como fazer uma leitura para distinguir quadros originais de cópias ou mesmo atribuir a autoria correta do quadro ao seu autor: 
(...) é preciso não se basear, como normalmente se faz, em características mais vistosas, portanto mais facilmente imitáveis, dos quadros: os olhos erguidos para o céu dos personagens de Perugino, o sorriso dos de Leonardo, e assim por diante. Pelo contrário, é necessário examinar os pormenores mais negligenciáveis, e menos influenciados pelas características da escola a que o pintor pertencia (ibidem, p. 144).

Ao longo de várias transformações na historiografia, a compreensão sobre os documentos históricos trouxe novas possibilidades de se relacionar com a história. Talvez a mais relevante tenha sido entender o documento como um diálogo entre o seu conteúdo, as intenções de quem o lê e os contextos em que vivem o autor do documento e o seu leitor. $\mathrm{Ou}$, ainda, um encontro entre a intencionalidade e a potencialidade do documento, sem ser capaz de dizer a verdade em seu sentido totalizante.

Olhar o passado por meio de uma fotografia é assumir que ele não é paralisado pela definição de um evento histórico, mas poder seguir rastros que atravessam décadas, pois se evidenciam por meio de enunciados que são retomados no tempo e no espaço. Nesse caminho, pode-se encontrar o poder de reversibilidade que a fotografia pode propor, perceber as possibilidades que vão além do registro fotográfico, ultrapassando a ilusória objetividade das imagens (FLUSSER, 1998).

Esses rastros são agentes de uma prática que se assemelha a uma costura, entretanto, de forma aparentemente desordenada, em que a realidade dos fatos são os fios usados na costura e a cada ponto costurado percebe-se a genealogia sendo construída. Unidos, os pontos são rastros e, como resultado, temos o acontecimento, um conceito que propõe outras leituras das ciências humanas e, no campo da história, coloca em xeque a construção habitual feita por meio das fotografias quando usadas como registros, considerados documentos históricos. As fotografias são portadoras desses rastros que possibilitam o entrelaçamento entre fatos registrados e novas narrativas, as fabulações possíveis. Portanto, os rastros são enunciados que se repropõem em diferentes tempos e espaços e constroem um acontecimento, supõem revisar o já acontecido, fazendo-o permanecer e acontecer.

Em contrapartida à ilusória objetividade das imagens, os rastros que podemos encontrar nas fotografias tornam o contexto fotográfico vivo em seus pormenores e revelam o que há de mais explícito neles. Rastros não podem ser silenciados, pois reclamam e insistem em uma possível história alternativa àquela já narrada.

Em seu exercício de fixação de longa duração, a fotografia experimenta, pela intencionalidade de quem a produz, sua face documental, quase impositiva. Entretanto, o faz por meio de mecanismos físicos e químicos, que vão além das habilidades do olho humano e por particularidades da própria técnica fotográfica, por meio de enquadramentos, angulações e composições.

(...) a fotografia revela nesse material os aspectos fisionômicos, mundos de imagens habitando as coisas mais minúsculas, suficientemente ocultas e significativas para encontrarem um refúgio nos sonhos diurnos, e que agora, tornando-se grandes e formuláveis, mostram que a diferença entre técnica e a magia é uma variável totalmente histórica (BENJAMIN, 1996, p. 94-95). 
Daí sua estranheza inicial e o estímulo que serviu como base para que novas perguntas fossem feitas sobre a fotografia, em especial aquelas que questionam seu valor único como documento: quando se revelam as coisas ocultas, capazes de gerar sonhos diurnos, a fotografia estaria apenas documentando?

\section{Rastros e índices}

Contribuindo para esses questionamentos, destacamos aqui as distinções entre o rastro e o indício, já que não são conceitos correspondentes. Pela definição de Carlo Ginzburg (2006) sobre rastros, são características pormenorizadas, sutis e opacas. No caso da fotografia, são particularidades não reprodutíveis e perceptíveis imediatamente que aguardam para serem notadas. Não são marcas que podem ser seguidas para então encontrar um resultado esperado, "mas se impõem como sugestões inferenciais que perseguem a imaginação, estimulando-a à produção/criação de semelhanças que, antilógicas, são sempre novas e diferentes" (FERRARA, 2018, p. 34).

Os indícios operam numa lógica de causa e efeito e contiguidade temporal. $\mathrm{Na}$ fotografia, o enquadramento executado e consequente recorte facilita o pensamento indiciário, pois o extraquadro pressupõe que a ação registrada tem continuidade fora do quadro, num efeito de contiguidade, como uma ligação entre aquilo que se vê e aquilo que não se vê na imagem. Além de operar numa lógica de causa e efeito, os índices, como sinais, fornecem certa dose de certeza ao referente fotográfico, talvez solidificando mais a ideia de registro fotográfico como documento.

Os rastros estão conectados ao próprio referente fotográfico, como os índices estão, mas estão aptos a deixá-los manifestar sua potência, e "apelam para a vigilância do pesquisador, não para perceber índices, mas para produzir relações hipotéticas" (idem, 2015, p. 129). Sendo assim, quando falamos de rastros, não é possível falar de apagamentos, recuperações, reaparecimentos, sobrevidas ou daquilo que restou, pois não é possível recuperar ou fazer reaparecer aquilo que nunca deixou de existir, que permanece, que vive e que lá, no passado, está, mas em potência; o que não cessa e o que continua a se reconfigurar imprevistamente.

Quando ressaltamos a necessidade de estabelecer aberturas, afirma-se o intuito de relacionar os conceitos de evento e acontecimento e, no último, entender como as dimensões do hipotético tomam lugar e permitem que possibilidades sejam exploradas - e até mesmo inventadas - no sentido de ampliar o evento. Falamos de um tipo de comunicação não transmissiva, que não se preocupa em apenas entregar a mensagem, mas deixá-la acessível aos interlocutores, para tornar possível uma coautoria. Não por acaso, existe uma relação íntima entre os rastros e o acontecimento:

Esfinge, o acontecimento é igualmente Fênix que na realidade nunca desaparece. Deixando múltiplos vestígios, ele volta constantemente, com sua presença espectral, para brincar com acontecimentos subsequentes, provocando configurações sempre inéditas. Nesse sentido, poucos são os acontecimentos sobre os quais podemos afirmar que terminaram porque estão ainda suscetíveis de novas atuações (DOSSE, 2010, p. 7). 
Naturalmente, as novas configurações suscitam perguntas vindas do desconhecido e impõem certa dose de dúvida. No entanto, a dúvida deve ser aliada aos estudos da comunicação, pois tem a capacidade de revisitar o tempo e, a cada tentativa, estipula novas configurações. Poderíamos dizer que a dúvida, elemento que acompanha o conceito de acontecimento, é adisciplinar, cabe a qualquer campo ou disciplina, transpassa qualquer fronteira entre disciplinas, pois, em realidade, trata-se de um investimento epistemológico que se concretiza entre investigações.

\section{As fotografias e o acontecimento}

Vejamos o caso das fotografias da Revolta de 1924 presentes neste artigo: possibilitam o acesso à destruição que a cidade sofreu, à observação que a população faz sobre o que vê, aos desfechos da revolta, a seu percurso ou parte dele, presente nos índices das ruas de São Paulo.
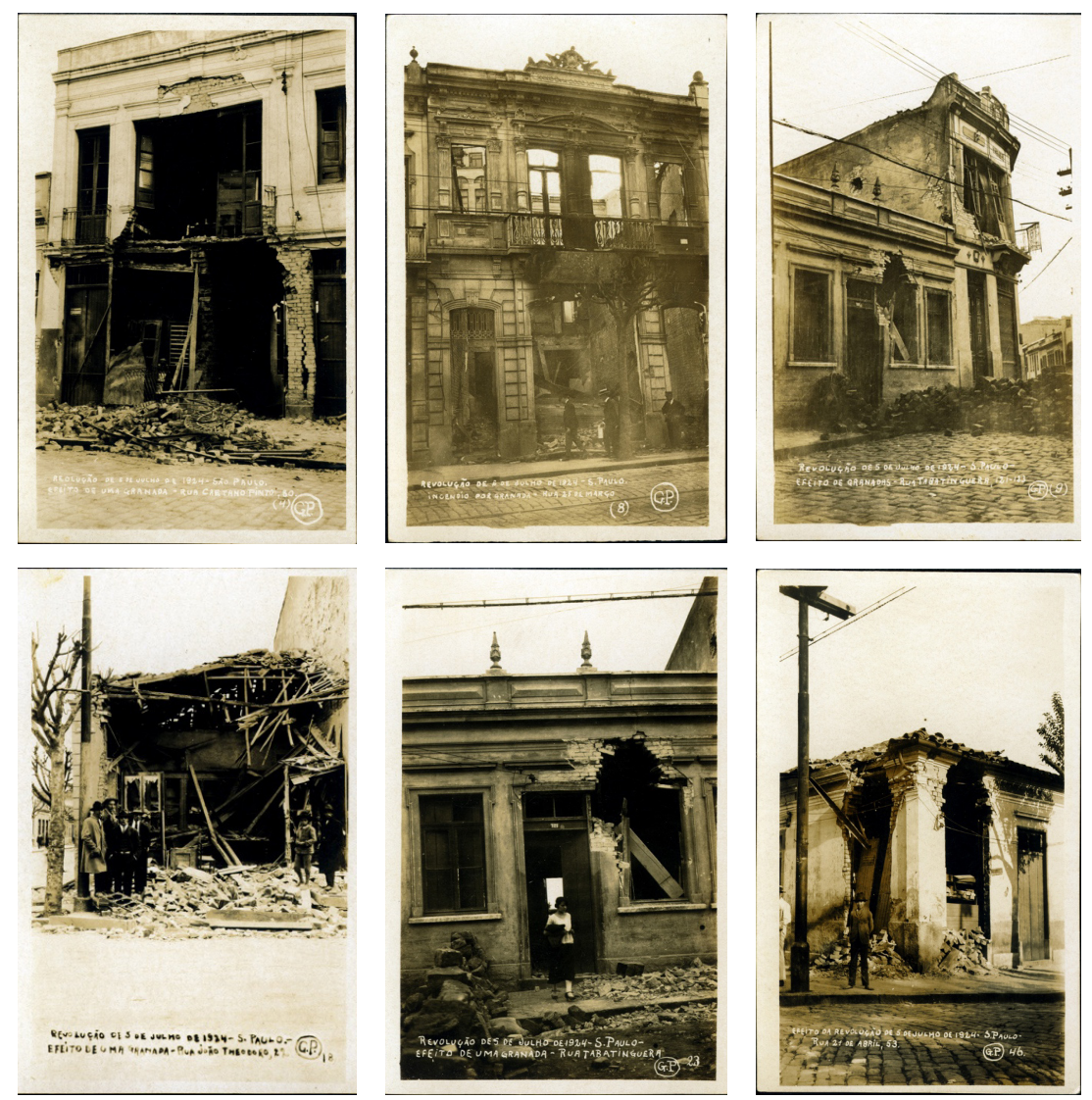

Fig. 4. Registros fotográficos de Gustavo Prugner, da esquerda para a direita: 1) Efeito de uma granada, rua Caetano Pinto, 80, São Paulo, 1924; 2) Incêndios por granada à rua 25 de março, São Paulo, 1924; 3) Efeitos de granadas na rua Tabatinguera, n.121-123, São Paulo, 1924; 4) Efeitos de uma granada na rua João Theodoro,n.22, São Paulo, 1924; 5) Efeitos de granadas na rua Tabatinguera, São Paulo, 1924; 6) Efeitos da Revolução de 1924 - Rua 21 de abril, São Paulo, 1924. Fonte: Acervo Instituto Moreira Sales, São Paulo, 2015 

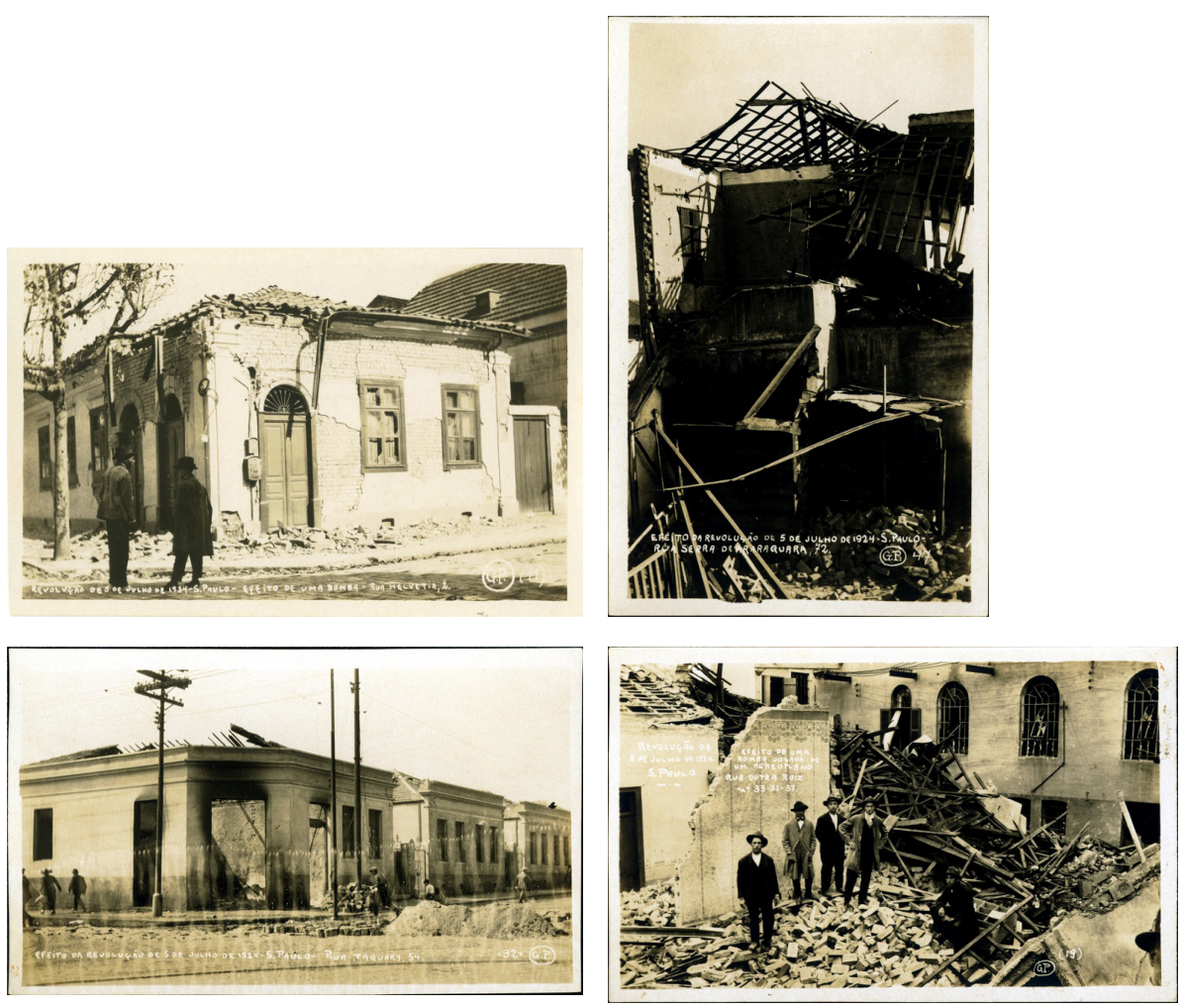

Fig. 5. Registros fotográficos de Gustavo Prugner, da esquerda para a direita: 1) Efeit Efeitos de uma bomba na ria Helvética, n.2, São Paulo, 1924; 2) Efeitos da Revolução de 5 de julho, Rua Serra de Araraquara, 72, São Paulo, 1924; 3) Efeitos da Revolução de 5 de julho, Rua Taquary, 54, São Paulo, 1924; 4) Efeito de uma bomba jogada de um aeroplano - Rua Dutra Roiz, n. 33-35-37, São Paulo, 1924.

Fonte: Acervo Instituto Moreira Sales, São Paulo, 2015

A noção de acontecimento possibilita descomprimir e ampliar o evento histórico, retirando-o do isolamento e proporcionando nova coordenação entre fatos. Ele não é um conteúdo estanque que marca um tempo ou data, não é contido, pois é pura potência, "o acontecimento é o que acontece e sua dimensão emergente ainda não está separada do passado" (DOSSE, 2010, p. 169). O exercício de investigação de um evento histórico, por meio de uma abordagem heurística, é resultado de uma operação reflexiva que, por vezes, ignora certos fatos para, cognitivamente, estabelecer novas coordenações que podem levar a outras descobertas. Os rastros que possibilitam as chaves de compreensão sobre o evento são produzidos cognitivamente e, quanto mais o evento se alarga, mais indefinição ganha, reduzindo-se as certezas em torno dele.

A evidência de que houve de fato um conflito armado na cidade está muito mais atrelada ao discurso oficial produzido sobre o evento do que revelada pelo que mostram as fotografias. Por conta desse dúbio registro, a fotografia pode acontecimentalizar o evento, pois inverte seu acordo estatutário clássico, ou seja, registra, mas não documenta. 
Lembramos que o fato de transformar o substantivo acontecimento em verbo já evidencia a ação epistemológica aqui proposta.

As fotografias de qualquer evento nos informam sobre o próprio evento e podem nos causar impactos da ordem da subjetividade. Também informam sobre a fotografia como um artefato de seu tempo. De fato, a fotografia promove registro de uma dada situação - física e quimicamente, ela consegue cumprir o contrato que lhe deu origem -, supera as tentativas que a pintura empreendia em fazer uma cópia da realidade e, efetivamente, como meio de expressão, ainda hoje carrega grande responsabilidade, por ser uma linguagem cada vez mais acessível e massiva. O discurso em torno da fotografia com excessiva racionalidade pode construir conceitos que a transformam em comprovação de fatos, evidências, testemunha de contexto, constatação da experiência ou registro de realidade. Ainda que essa noção de fotografia como registro da realidade, para alguns autores, já tenha sido superada, ela ainda paira, às vezes sutilmente, sobre um modo de pensá-la.

Para Joan Fontcuberta (2010), um dos autores que afirmam que essa superação já ocorreu, "a descontextualização não apenas modifica um valor de uso, mas também, principalmente, pulveriza a própria noção de que a fotografia é prova de alguma coisa, o suporte de uma evidência" (ibidem, p. 44). Esse movimento de pulverização a que o autor se refere pode ser entendido como uma nova percepção das informações que a fotografia produz, sua percepção visual é a associação do verbal com o conceitual.

O insight que levou a essa tentativa atual de vincular a linguagem verbal com a da expressão artística foi a constatação de que as artes visuais e a música são ambas baseadas na percepção, pela fisicalidade do meio (médium) artístico e, o mais importante, também conceituais, por causa da natureza simbólica e representacional das formas de artes (LOGAN, 2012, p. 240-241).

Acrescentaria que, não só nas formas artísticas, mas também na comunicação, as informações presentes na fotografia, quando pulverizadas, são lançadas para novos contextos, responsáveis por Ihes determinar novo caráter. Essa linguagem multidimensional permite que a representação seja capaz de propor outras realidades, agora transformadas por novos contextos, que influenciam diretamente o processo de informação dessas imagens que registram a Revolta. Pulverizadas as informações originais ou primeiras, o que a fotografia está apta a documentar? Diante desse impasse, resta à fotografia assumir seu potencial criador de novos possíveis sobre seu referente, daí a noção de a fotografia acontecimentalizar eventos históricos, colocando suas versões oficiais em dúvida.

Na imprevisível flutuação dos rastros, terreno propício para o acontecimento, e além das evidências, é possível tatear a superação da fotografia como documento. A fotografia é um meio técnico e um meio comunicativo capaz de criar seu próprio ambiente para se comunicar e, sendo meio, é também a própria mensagem (MCLUHAN, 1969), criando seus próprios acessos para que possamos inventá-la e fabulá-la. 
O documento traz consigo a possibilidade de expor quem faz sua leitura e a época em que foi feita, o que significa também ressaltar toda parcialidade presente em documentos históricos. O mesmo se aplica à fotografia, um registro elaborado por um sujeito que fala sobre si e sobre seu tempo. Assim, refuta-se a objetividade dos documentos, pois concordamos que a historiografia tem componentes subjetivos, como nos mostra Carlo Ginzburg (2006, p. 265) em seu processo de escrita da obra O queijo e os vermes: "(...) as hipóteses, as dúvidas, as incertezas tornavam-se parte da narração; a busca da verdade torna-se parte da exposição da verdade obtida (e necessariamente incompleta)".

Em vista desse componente, apresenta-se a ambivalência dos documentos que é explorada pelo historiador em sua obra. A ambivalência não contrapõe e não opera com oposições ou dicotomias entre categorias existentes num mesmo objeto ou documento, ela é condição da linguagem e pressupõe aceitar o desconforto causado por seu natural rompimento com a ordem estabelecida: a da certeza. "A ambivalência é, portanto, o alter ego da linguagem e sua companheira permanente - com efeito, sua condição normal" (BAUMAN, 1999, p. 9). Por isso uma abordagem empírica com relação às fotografias se faz necessária, a fim de apreender as experiências que essas fotografias da Revolta de 1924 de fato propõem, quando não mostram a revolta.

\section{As fotografias e a fabulação}

São as próprias fotografias da Revolta que trazem à tona a possibilidade de estabelecer outra narrativa; são elas que propõem, sugerem e especulam outra perspectiva sobre o levante e se apresentam como frágeis documentos da história, porque mostram a destruição de casas e bairros, ou mesmo um momento em que a tropa se alimentava, mas não são capazes de ser documentos que mostrem a revolta acontecendo. Elas fornecem elementos de invenção que desestabilizam a narrativa histórica clássica ou oficial sobre o evento, e isso ocorre quando revelam o cotidiano da revolta e seus bastidores, com foco nas perspectivas de rotina da cidade, muito mais do que na violência e no medo da revolta: a população parece conviver com o conflito sem temer.

As fotografias falham ou traem seu valor documental em relação à Revolta, já que nelas não há comprovação de conflitos. Há, sim, o registro sobre a cidade e seus moradores, sobre os próprios fotógrafos e até sobre as possíveis relações ainda submersas nessas fotografias.

Como o ser não se reduz ao ente, o acontecimento não se reduz a sua acontecimentalidade (evenementialité) e seu sentido excede em todos os sentidos o que é comprovado. A compreensão, a descoberta de um sentido se assimila, portanto, ao próprio acontecimento de revelação do ser (...) (DOSSE, 2010, p. 95).

Nas fotografias é possível ver a Revolta sob outras perspectivas, algo que indica um descompasso implícito na relação entre registro e documento, um descompasso próprio 
do meio técnico, pois quer construir e mostrar um cenário de horror, mas, ao mesmo tempo, revela um confronto que acontece à revelia da população e, talvez, do interesse do fotógrafo. Um descompasso que também pode revelar a possibilidade do emaranhado existente entre realidade e ficção e que muitas vezes funciona como base para a construção das fábulas, como gêneros narrativos, por exemplo.

No gesto fotográfico está presente a competência técnica, mas também a imaginação incalculável que "desmente todo o realismo e idealismo" (FLUSSER, 2002, p. 32). A fotografia está longe de ser apenas espelho refletindo de forma integral a realidade, tal como tenta, algumas vezes, um documento. Qualquer tentativa de integralidade do documento, fotográfico ou não, no sentido de sua compreensão é, na verdade, não o aceitar como portador de ruídos que auxiliam sua compreensão. Por isso, quando se alarga o evento, perdem-se algumas definições sobre ele e as narrativas oficiais se desconstroem e não sobrevivem às dúvidas e às incertezas, resultados desse alargamento e dos ruídos que dele emergem. Alargado, o evento rompe seus próprios limites convertendo-se em acontecimento.

Portadora dessa acontecimentalização, a fotografia traz rastros que propõem uma coordenação entre fatos e experiências, uma nova costura. Esse emaranhado entre realidade e ficção se encarrega de estabelecer uma organização, no sentido de torná-la viva, presente e passível de intercâmbios com qualquer tempo. A coordenação de rastros requer investigação sobre o que antes não foi indagado, tornando possível a dúvida que permite rever o passado. À medida que se contesta o já existente, as possibilidades se abrem cada vez mais. "O acontecimento é o que remete a um verdadeiro reencontro com a alteridade, a um outro dinamismo, a uma primeira vez, à imanência de uma recepção plena, inteira" (DOSSE, 2010, p.87).

A narrativa se vale, muitas vezes, desse emaranhado de elementos da realidade e da ficção, entendendo que a imaginação é a substância da ficção e um dos lugares para o exercício da alteridade. Quando realidade e ficção são colocadas nessa dinâmica de entrelaçamento, é quase impossível não assumir a dúvida que surge dessa nova costura e, assim sendo, o outro estará presente na condição da diferença, o que mostra, talvez, a grande semelhança entre os indivíduos.

A narrativa "(...) não se entrega. Ela conserva suas forças e depois de muito tempo ainda é capaz de se desenvolver" (BENJAMIN, 1996, p. 204). Parte dessa possibilidade de recomposição das narrativas está ligada à percepção dos rastros, assim como a um certo grau de imaginação, como um modo investigativo. No caso das fotografias da Revolta de 1924, os fotógrafos narram o conflito vivido pela e na cidade e, ao mesmo tempo, são moradores da cidade conflagrada, ou seja, suas experiências também estão presentes nas fotografias.

Os rastros podem ser percebidos como fragilidades por serem ocultos ou não perceptíveis e, talvez por isso, questionáveis ainda que reveladores. Nessa revelação de detalhes submersos nas grandes narrativas oficiais presentes nos documentos, estão as potencialidades para que outras sejam produzidas. Um exemplo que ilustra essa 
possibilidade é a obra de Carlo Ginzburg (2006) O queijo e os vermes. Nela o autor, além de reconstruir a história de um moleiro na Idade Média, também a insere num quadro narrativo e, dessa forma, estabelece continuidade e ordenação.

Ao mirar esses rastros e admiti-los numa outra narrativa composta associativamente por uma genealogia de rastros, assumimos a potencialidade de criação e da imaginação, que vai além da objetividade fotográfica para atingir a subjetividade, num processo de invenção e não mais de documentação. Ao descobrir essa potência da fotografia, é possível que se estabeleçam outras narrativas sobre o evento, por exemplo, uma revolta de menores proporções ou com poucos efeitos sobre a população ou, ainda, uma convivência pacífica entre revoltosos e população, o que poderia estabelecer outras versões sobre a historiografia da Revolta. Dessa maneira, a Revolta de 1924 seria acontecimentalizada por meio de uma outra abordagem, a fabulação, que, nessa proposta, seria fotográfica e não verbal.

Para a ideia de novos possíveis e outras narrativas, é imprescindível estabelecer a rota de fuga daquilo que se apresenta como determinado e previsível, como um evento histórico que é registrado pela fotografia, que o documenta. Neste caso, trata-se de contestar o evento e a fotografia como seu documento responsável por provar sua ocorrência e estabelecer outro rumo narrativo, partindo em direção ao acontecimento e à fabulação. Esse rumo desobedece ao discurso da fotografia como documento e, como consequência, questiona o evento como narrativa unívoca sobre os fatos históricos.

Essa desobediência também está associada a outra abordagem epistemológica, devido à necessidade de se questionar um pensamento dado como certo, colocá-lo em estado de dúvida e talvez até negá-lo. A fotografia ainda é entendida como um registro-documento e esse ponto de vista faz com que sua análise careça de outras epistemologias que podem levá-la ao desenvolvimento da potência que nos permite fabular a partir dela e imaginar elementos que estão presentes, ainda que pouco evidentes ou ausentes no registro.

Quando um evento passa a ser acontecimentalizado, ganha atualidade imprevista, pois sua narrativa continua a se desenvolver e, nesse sentido, os rastros mostram o quanto sua força está mantida para que possa ainda seguir se desenvolvendo, aberto a novas possibilidades. Daí o valor do trabalho genealógico: a manutenção da imprevisibilidade e da dúvida na construção de novos possíveis e outras narrativas/fabulações para a história ou para a comunicação, pois "o que a ciência constatou, a rememoração pode modificar" (BENJAMIN, 2007, p. 489).

Maria Cecilia Conte Carboni é professora da Universidade Paulista e do Centro Universitário FAM. É doutora pelo Programa de Pós-Graduação em Comunicação e Semiótica da Pontifícia Universidade Católica de São Paulo. É jornalista e roteirista e membro do ESPACC - Espaço Visualidades Comunicação e Cultura.

cicacarboni@gmail.com 


\section{Referências}

BAUMAN, Z. Modernidade e ambivalência. Rio de Janeiro: Jorge Zahar Editor, 1999.

BENJAMIN, W. Obras escolhidas: magia, técnica, arte e política. São Paulo: Editora Brasiliense, 1996. Passagens. Belo Horizonte: UFMG Editora, 2007.

BLOCH, M. Apologia à história. Rio de Janeiro: Zahar Editora, 2002.

BURKE. P. A escrita da história: novas perspectivas. São Paulo: Editora UNESP, 1991.

CHARTIER, R. Verbete Imagens. In: BURGUIÈRE, André. Dicionário das ciências históricas. Rio de Janeiro: Imago, 1993.

COHEN, I. Bombas sobre São Paulo. São Paulo: Editora UNESP, 2007.

CORREA, A. A rebelião de 1924 em São Paulo. São Paulo: Higitec, 1976.

DIDI-HUBERMAN, G. O que vemos, o que nos olha. São Paulo: Editora 34, 2010.

DOSSE, F. Renascimento do acontecimento. São Paulo: Editora UNESP, 2010.

FERRARA, L. D. Comunicação, mediações, interações. São Paulo: Paulus, 2015.

. A comunicação que não vemos. São Paulo: Paulus, 2018.

FRIZOT, M (Org). Nouvelle histoire de la photographie. Paris: Adan Biro/ Larousse, 2001.

FLUSSER, V. Filosofia da caixa-preta: ensaios para uma futura filosofia da fotografia. Rio de Janeiro: Sinergia Relume Dumará, 2002.

Ensaio sobre a fotografia. Lisboa: Relógio D’água editores, 1998.

FONTCUBERTA, J. O beijo de Judas: fotografia e verdade. Barcelona: GG, 2010.

GINZBURG, C. Os fios e os rastros: verdadeiro, falso, fictício. São Paulo: Companhia das Letras, 2006. Mitos, emblemas, sinais. São Paulo: Companhia das Letras, 1989.

KOSSOY, B. Fotografia \& história. 5ª ed., São Paulo: Ateliê Editorial, 2014.

LAZZARATO, M. As revoluções do capitalismo. Rio de Janeiro: Civilização Brasileira, 2006.

LE GOFF, J. História e memória. Campinas, SP: Editora UNICAMP, 1990.

LOGAN, R. O que é informação. Rio de Janeiro: Editora PUC Rio, 2012.

MCLUHAN, M.; FIORE, Q. O meio são as mensagens. Rio de Janeiro: Record,1969.

NORA, P. Historiens, Photographes: Voir et Devoir. In: CAUJOLLES, Cristian (dir.). Éthique, esthétique, politique. Arles: Actes Sud, 1997.

PEREIRA, D. P. 1924 O Diário da Revolução: Os 23 dias que abalaram São Paulo. São Paulo: Imprensa Oficial, 2010.

SEVCENKO, N. Orfeu extático na metrópole: São Paulo, sociedade e cultura nos frementes anos 20. São Paulo: Companhia das Letras, 1992.

VEYNE, P. Como se escreve a história e Foucault revoluciona a História. Brasília: Editora UnB, 1998. 